\title{
A 'two-in-one' foreign body coin in oesophagus: A case report
}

\author{
${ }^{1}$ Dr. SeikholetKuki, ${ }^{2}$ Dr. A. Gulati. \\ ${ }^{1,2}$ Department of Otorhinolaryngology, MAMC Look Nayak Hospital, New Delhi, India..
}

\begin{abstract}
Though foreign bodies are frequently inadvertently placed by children in their ears or noses and occasionally are swallowed, the presence of two coins appearing as single radio opaque shadow on X-ray can be both confusing and interesting case at times. Ingestion of foreign bodies is a cause of morbidity and mortality in paediatric population. The most common paediatric foreign bodies ingested are coins; followed by a variety of other objects, such as plastic toys or toy parts, sharp objects, button batteries, bones, and food. Information from witnessed ingestion, and a high level of clinical suspicion can prevent delays in diagnosis and complications related to these delays. Ingestion of foreign bodies is an avoidable accident that is seen mainly in children less than 3 years of age.
\end{abstract}

Key words: Check Oesophagoscopy, Double coin, Endoscopy, Foreign body, Oesophagus,

\section{Introduction}

Children under 3 years of age have a high propensity of placing objects in their mouth. Incomplete dentition and immature swallowing coordination may also play a role ${ }^{1}$. Coin ingestion is the most common foreign body in children ${ }^{2}$ however the presence of two coins in oesophagus is,to our knowledge not beenpreviously reported so far. In this article we report a case of two coins superimposed on each other as a single looking radio-opaque oesophageal foreign body on plain chest X-ray films. Some foreign bodies may pass through the digestive tract without causing clinical manifestations or complications, but a significant percentage may get impacted in the oesophagus especially the cervical oesophagus. ${ }^{4}$ Complications usually occur when there is a delay in diagnosis. Oesophageal foreign bodies need immediate attention and urgent intervention due their potential airway and gastrointestinal complications.

\section{Case Report}

An otherwise healthy 9 year-old boy presented to the ENT emergency department 12hours after accidental foreign body ingestion. On examination, patient was apparently well except for decreased oral acceptance and history of repeated episodes of vomiting. Patient was put nil per orally and on IV fluid. A plain chest X-ray PA and lateral views was taken which showed about $2.5 \mathrm{~cm}$ diameter radio opaque round object in the upper oesophagus suggestive of coin.Diagnosis of oesophageal foreign body coin was made. Full consent was taken from the child's parents and he was taken up for an urgent rigid esophagoscopy under general anaesthesia which was performed 2hours after admission. Oesophagoscopy findings confirm coin in the cricopharynx at a level of $17 \mathrm{~cm}$ from the incisor teeth. A one rupee coin was removed. Surprisingly on check oesophagoscopy another coin was identified and extracted. It was a two rupee coin. A further check oesophagoscopy up to the stomach revealed no evidence of mucosal injury or foreign body. Patient extubation was uneventful. Post-operative management included fasting, administration of intravenous antibiotic therapy, painkiller and antacids. A repeat X-ray chest and abdomen post operatively was clear of radio-opaque shadows. The patient was allowed orally the next day and discharged following uneventful hospital stay. Follow up after a week was uneventful.

Plain X-Rays:

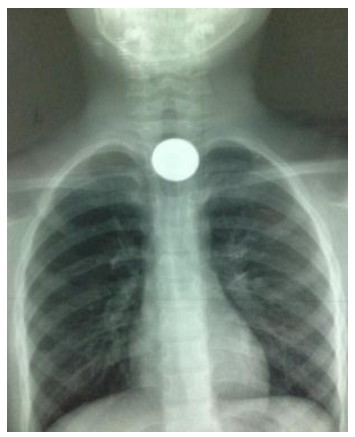

Fig.1. FB coin in postero-anterior view 


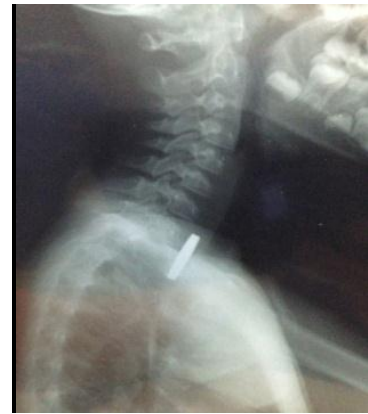

Fig 2. Lateral view

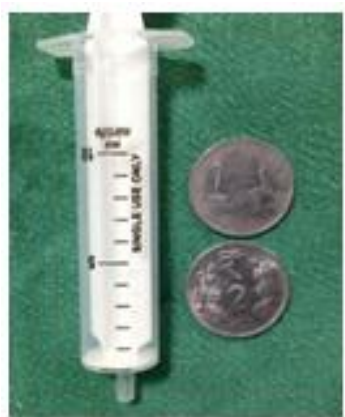

Fig 3.Extracted F.B Coins (A $2.5 \mathrm{~cm}$ size each of $1 \& 2$ Indian rupee coins)

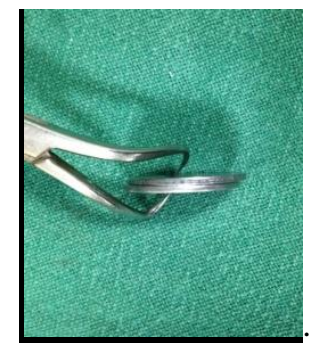

Fig 4. Coins held together (depicting single shadow on X-ray film above)

\section{Discussion}

Children of all ages ingest foreign bodies. However, incidence is greatest in children aged 6 months to 4 years. It is because they lack adequate dentition, swallowing capabilities, judgement and increased mobility. ${ }^{1}$, ${ }^{5}$ Most ingestions (40\%)are not witnessed and remain asymptomatic, therefore a high level of clinical suspicion is needed. ${ }^{2}$ Coins are the most common oesophageal foreign body. ${ }^{2,3}$ Typical signs and symptoms of oesophageal foreign bodies are drooling, dysphasia, weight loss, emesis, unexplained fever, chest pain and compressive airways symptoms. ${ }^{6}$

Most foreign bodies get impacted in the upper oesophagus which is at the level of thoracic inlet. This is the site of anatomical change from the skeletal muscle to the smooth muscle of the oesophagus. The cricopharyngeus sling may "catch" about 70\% of blunt foreign bodies here. Mid oesophagus accounts for 15\% where the aortic arch and carina overlap the oesophagus on chest radiograph. The lower oesophageal sphincter

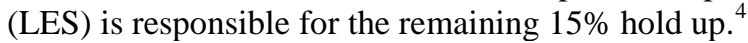

Oesophageal foreign bodies can damage the oesophagus and lead to strictures, tracheoesophageal fistulas. Oesophageal foreign body migration may lead to peritonitis, mediastinitis, pneumothorax,pneumomediastinum, pneumonia, or other respiratory disease. Migration into the aorta may produce an aortoenteric fistula, a horrific complication with a high mortality rate. Unlike coins oesophageal button batteries may cause significant mucosal injury in as few as 2 hours. ${ }^{7,8}$

Once a swallowed foreign body reaches the stomach it is less likely to lead to complications. Foreign bodies occasionally become lodged at the ileocecal valve. ${ }^{9}$ Retained foreign bodies may cause GI mucosal erosion, abrasion, local scarring, or perforation. Coins made largely from zinc may interact with stomach acid leading to stomach ulceration, pressure necrosis, fistula creation, or perforation. ${ }^{10,}{ }^{11}$ Magnetic components in toys may attract and adhere to each other leading to small bowel obstruction or necrosis, sometimes with severe sequelae. ${ }^{12}$ 
Spontaneous coin passage rates range widely from 9-77\% in this patient population. Most objects will pass within four to six days of ingestion, but some may take up to four weeks. In children one year of age and older, objects longer than 3 to $5 \mathrm{~cm}$ may not pass, and hence endoscopic removal should be considered.The traditional use of glucagon is not effective inadvancing foreign bodies into the stomach. ${ }^{13},{ }^{14}$ Button batteries, sharp objects and foreign body that have been lodged in the oesophagus for more than 24 hours or for an unknown duration require urgent endoscopic removal to avoid mucosal erosion or peforation. ${ }^{15},{ }^{16}$ All other foreign bodies lodged in the oesophagus should be removed or advanced into the stomach.Most blunt objects in the distal oesophagus may be observed for up to 24 hours. If the object fails to pass into the stomach, it should be removed or possibly pushed into the stomach. The Foley, bougienage and flexible endoscopy techniques have been proposed to remove coins and similar smooth objects from the oesophagus. ${ }^{17}$ Because endoscopy generally is the preferred and accepted method of removing coins from the oesophagus, strict criteria should be used when considering other methods. ${ }^{18}$

In the pre-endoscopy era, 93 to 99 percent of blunt objects passed without intervention, and approximately one percent required surgical removal. Today, 10 to 20 percent of children who ingest foreign bodies are managed with endoscopy. ${ }^{19}$

\section{Conclusions}

Though most foreign body coins can be successfully managed by endoscopic retrieval under general anaesthesia, diagnosis can be confusing with button battery on X-ray film. A double coin can resemble that of button battery in terms of size and thickness on a radiological film to an unsuspecting or inexperienced surgeon. Therefore it is of utmost importance to differentiate between the two entities by trained and experienced radiologist. Radiographs should be examined for the battery's double-rim or halo effect on the anteroposterior view or step-off on the lateral view. A thorough check and a re-check oesophagoscopy may save the day when in doubt. Post-operative X-ray is helpful. Early detection remains the key in the management to improve outcome. While most children will make full recovery without any sequelae, delays in the diagnosis may cause severe morbidity. The parents and child care providers should be educated about the potential danger.

\section{References}

[1]. Crysdale WS, Sendi KS, Yoo J. Esophageal foreign bodies in children: 15-yer review of 484 cases. Ann OtolRhinolLaryngol, 100, $1991,320$.

[2]. Dahshan A. Management of ingested foreign bodies in children. J Okla State Med Assoc, 94, 2001, $183-6$.

[3]. Conners GP, Chamberlain JM, Weiner PR. Pediatric coin ingestion: a home-based survey. Am J Emerg Med, 13(6), 1995, 638-40.

[4]. Litovitz T, Whitaker N, Clark L, White NC, Marsolek M. Emerging battery-ingestion hazard: clinical implications. Pediatrics, 125(6), 2010, 1168-77.

[5]. Susy Safe Working Group. The Susy Safe project overview after the first four years of activity. Int J PediatrOtorhinolaryngol, 76 (1), 2012, S3-11.

[6]. Arana A, Hauser B, Hachimi-Idrissi S, Vandenplas Y. Management of ingested foreign bodies in childhood and review of the literature. Eur J Pediatr, 160, 2001, 468-72.

[7]. Chen MK, Beierle EA. Gastrointestinal foreign bodies. Pediatr Ann,30, 2001,736-42.

[8]. Byerley JS. Pediatric emergencies in the family practice clinic. ClinFamPract, 5, 2003,445-66.

[9]. Pavlidis TE, Marakis GN, Triantafyllou A, Psarras K, Kontoulis TM, Sakantamis AK. Management of ingested foreign bodies. How justifiable is a waiting policy?. SurgLaparoscEndoscPercutan Tech, 18(3), 2008,286-7.

[10]. Vijaysadan V, Perez M, Kuo D. Revisiting swallowed troubles: intestinal complications caused by two magnets--a case report, review and proposed revision to the algorithm for the management of foreign body ingestion. J Am Board Fam Med, 19(5), 2006, 511-6.

[11]. Fenton SJ, Torgenson M, Holsti M, Black RE. Magnetic attraction leading to a small bowel obstruction in a child. PediatrSurg, 23(12), 2007, 1245-7.

[12]. Pryor HI 2nd, Lange PA, Bader A, Gilbert J, Newman K. Multiple magnetic foreign body ingestion: a surgical problem. J Am CollSurg,205(1), 2007, 182-6.

[13]. Mehta D, Attia M, Quintana E, Cronan K. Glucagon use for esophageal coin dislodgement in children: a prospective, double-blind, placebo-controlled trial. AcadEmerg Med, 8, 2001,200-3.

[14]. Duncan M, Wong RK. Esophageal emergencies: things that will wake you from a sound sleep.GastroenterolClin North Am, 32, 2003,1035-52.

[15]. Eisen GM, Baron TH, Dominitz JA, Faigel DO, Goldstein JL, Johanson JF, et al. Guideline for the management of ingested foreign bodies. GastrointestEndosc, 55, 2002,802-6.

[16]. Waltzman ML, Baskin M, Wypij D, Mooney D, Jones D, Fleisher G. A randomized clinical trial of the management of esophageal coins in children. Pediatrics, 116(3), 2005, 614-9.

[17]. Soprano JV, Mandl KD. Four strategies for the management of esophageal coins in children.Pediatrics, 105, 2000 , e5.

[18]. Calkins CM, Christians KK, Sell LL. Cost analysis in the management of esophageal coins: endoscopy versus bougienage. J PediatrSurg, 34, 1999,412-4.

[19]. Chen MK, Beierle EA. Gastrointestinal foreign bodies. Pediatr Ann, 30, 2001,736-42. 